\title{
The role of NMDA receptor antagonists, amantadine and memantine, in schizophrenia treatment: a systematic review
}

\author{
BRUNO TERRA JUNHO ${ }^{1}$ \\ https://orcid.org/0000-0003-3677-7383 \\ Victor FERNANDES DE OLIVEIRA 2 \\ https://orcid.org/0000-0003-3156-0249 \\ - Department of Mental Health, Faculty of Medical Sciences of Minas Gerais, Belo Horizonte, MG, Brazil. \\ 2 Department of Clinical and Toxicological Analyses, School of Pharmaceutical Sciences, University of São Paulo, São Paulo, SP, Brazil.
}

Received: 12/27/2018 - Accepted: 09/17/2019

DOI: 10.1590/0101-60830000000218

\begin{abstract}
Objective: Schizophrenia is a complex and chronic psychiatric disorder. In recent years, studies have found glutamatergic system participation in its etiopathogenesis, especially through aberrant NMDA receptors functioning. Thus, drugs that modulate this activity, as amantadine and memantine, could theoretically be used in its treatment. To perform a systematic literature review about memantine and amantadine use as adjunct in schizophrenia treatment. Methods: A systematic review of papers published in English indexed in the electronic database PubMed" using the terms "memantine", "amantadine" and "schizophrenia" published until October 2016. Results: We found 144 studies, 8 selected for analysis due to meet the objectives of this review. Some of these have shown benefits from such drug use, especially in symptoms measured by PANSS and its subdivisions, while others do not. Discussion: The data in the literature about these drugs use for schizophrenia treatment is still limited and have great heterogeneity. Thus, assay with greater robustness are needed to assess real benefits of these drugs as adjuvant therapy.
\end{abstract}

Junho BT et al. / Arch Clin Psychiatry. 2019;46(6):165-8

Keywords: Schizophrenia, memantine, amantadine.

\section{Introduction}

Schizophrenia is a complex and heterogeneous psychiatric disorder characterized by an intriguing constellation of symptoms that are classically grouped into three main categories, positive (delusions and hallucinations), negative (apathy, social withdrawal and emotional blunting, for example) and cognitive symptoms (wide range of constituent elements, such as attention and memory impairments) ${ }^{1}$. This condition has a chronic course and important impact on this patients' lives and currently is among the ten most disabling diseases ${ }^{2}$.

Despite the extensive efforts that have been made in therapeutic approaches, treatment still faces events that have not been overcome yet. The broad side effects profile of drugs available, the absence of well-established treatments for some disease dimensions, such as cognitive symptoms, and the modest response in the control of positive symptoms in refractory cases are some of these examples ${ }^{1}$. It is estimated that one-fifth to one-third of patients do not respond adequately to drug treatment ${ }^{3}$. Therefore, new drugs research is a pressing need and a deeper understanding of its pathophysiology is essential for this achievement.

Neurobiological processes comprehension underlying the schizophrenia has advanced immensely in the last decades with the new methodological approaches' development. Initially, only the dopaminergic hyperactivity in the mesolimbic pathway had been described. However, recent evidence points to the involvement of glutamatergic pathways and glutamate receptors, especially the $\mathrm{N}$-methyl-D-aspartate glutamatergic receptors (NMDAr), in its pathogenesis 4 .

As a main excitatory neurotransmitter, glutamate performs several functions in human brain such as attention ${ }^{5}$, memory and cognition processes ${ }^{6,7}$. Nevertheless, high glutamate levels overactive their receptors inducing neuronal damage, a process known as excitotoxicity, due to high calcium influx ${ }^{8}$. Glutamate receptors were divided basically in two different types: metabotropic and ionotropic receptors. The glutamate metabotropic receptors are members of a receptor group coupled to G-protein. When this receptor is activated, a signal transduction cascade starts resulting various changes inside the neuron. Others receptors, such as $\alpha$-amino-3-hydroxy-5-methyl4-isoxazolepropionic acid receptor (AMPAr), kainate and NMDAr, are classified as ionotropic receptors, i.e., a receptor linked to an ionic channel 6,9 .

There are various glutamatergic pathways in human brain. Among them, it is important to highlight the cortico-cortical pathways. In prefrontal cortex, glutamatergic neurons establish synapses with parvoalbumin-containing gamma-aminobutyric acid (GABA) interneuron. Then, this interneuron connects with another glutamatergic neuron that directs to the nucleus accumbens in the brainstem. This last neuron forms a synapsis with a dopaminergic neuron of mesolimbic pathway. These intricate connections are the link between glutamatergic and dopaminergic pathways. Therefore, the decrease in GABAergic activity in this pathway consequently increases the activity on the mesolimbic pathway as observed in schizophrenia ${ }^{10}$. In fact, the administration of phencyclidine and ketamine, dissociative anesthetics and NMDAr antagonists, causes psychotic, negative ${ }^{7}$ and cognitive symptoms $s^{8,9}$ development in healthy subjects and in animal models. Moreover, evidence supports the NMDAr autoantibodies involvement on lupus psychosis development ${ }^{10}$.

Hence drugs that modulate this pathway hypothetically could mitigate the symptoms observed in patients with schizophrenia. Amantadine and its derivate, memantine, show this ability. These drugs are NMDAr antagonists with moderate affinity and rapid receptor dissociation property leading to a sustained trait to block pathological hyperactivity, but not compromising physiological activity ${ }^{11}$.

Thus, memantine and amantadine, NMDAr antagonists, are possible agents to be evaluated for schizophrenia treatment by their ability to modulate glutamatergic system ${ }^{12}$, besides possessing neuroprotective activity ${ }^{13}$ and improve cognitive deficits and memory ${ }^{14}$. This paper aims to conduct a systematic review of the 
scientific literature about memantine and amantadine use for schizophrenia treatment.

\section{Methods}

The data collected for this systematic review followed the Preferred Reporting Items for Systematic Reviews and Meta-analyzes (PRISMA) guidelines and the flowchart for paper selection can be found summarized in Figure 1.

\section{Search strategy}

The electronic database PubMed ${ }^{\oplus}$ was used twice. In the first step, the terms "schizophrenia" and "memantine" were used and, in the second step, "schizophrenia" and "amantadine". These terms were selected from the Medical Subject Headings (MeSH) to identify relevant studies.

The search for the items took place in the first October week in 2016. The papers analyzed were published in English and were from 1968 until the completion of this study.

\section{Eligibility}

The criteria listed below were used for studies inclusion or exclusion in this review:

a) Type of study: Were selected double-blind, placebo-controlled, randomized clinical trials;

b) Types of participants: The selected clinical trials involved patients with schizophrenia or related disorders diagnosis of any age or sex in antipsychotic treatment;

c) Intervention type: All studies involving amantadine or memantine use in combination with antipsychotics, regardless of dose and regimen, used in any form of administration, and duration compared with placebo or another agent;

d) Outcome: The selected studies sought to demonstrate the possible effects of amantadine or memantine use on positive, negative or cognitive symptoms in its various aspects.

\section{Results}

\section{Research and study results}

Using the above terms were identified 144 studies, 42 related to memantine and 102 related to amantadine. Of these 31 were excluded because they were duplicate. After abstract analysis, we excluded 105 items because they did not meet the eligibility conditions mentioned in the methods. Subsequently, the remaining 8 papers were fully analyzed. Figure 1 explains the various steps involved in this selection.

\section{Studies analysis}

Table 1 outlines the selected study's findings.

\section{Memantine}

Were found 4 studies ${ }^{14-17}$ that evaluated memantine use in schizophrenia or related disorders treatment. They consisted in randomized, double-blind, placebo-controlled trials, one of which featured crossover mode ${ }^{14}$. Their duration ranged between 8 to 26 weeks with memantine use of $20 \mathrm{mg}$ per day. In all of them there were atypical antipsychotics use: one had varied use ${ }^{16}$, two had clozapine treatment ${ }^{14,15}$ and one had risperidone use ${ }^{17}$.

Lieberman et al. ${ }^{16}$ evaluated memantine use in combination with atypical antipsychotics and found that there was no significant difference compared to placebo in the total, positive and negative scores of Positive and Negative Syndrome Scale (PANSS) and Calgary Depression Scale for Schizophrenia (CDSS) scores. However, memantine use was more associated with occurrence of side effects. Already Rezaei et al. ${ }^{17}$ conducted a study in Iran involving 40 participants and its association with risperidone. This assay had 8 weeks duration and observed an improvement in PANSS total and negative scores. There was no observed statistically significant change compared to placebo in PANSS positive, Hamilton Depression Rating Scale and Extrapyramidal Symptom Rating Scale. Furthermore, incidence of side effects was similar between two groups.
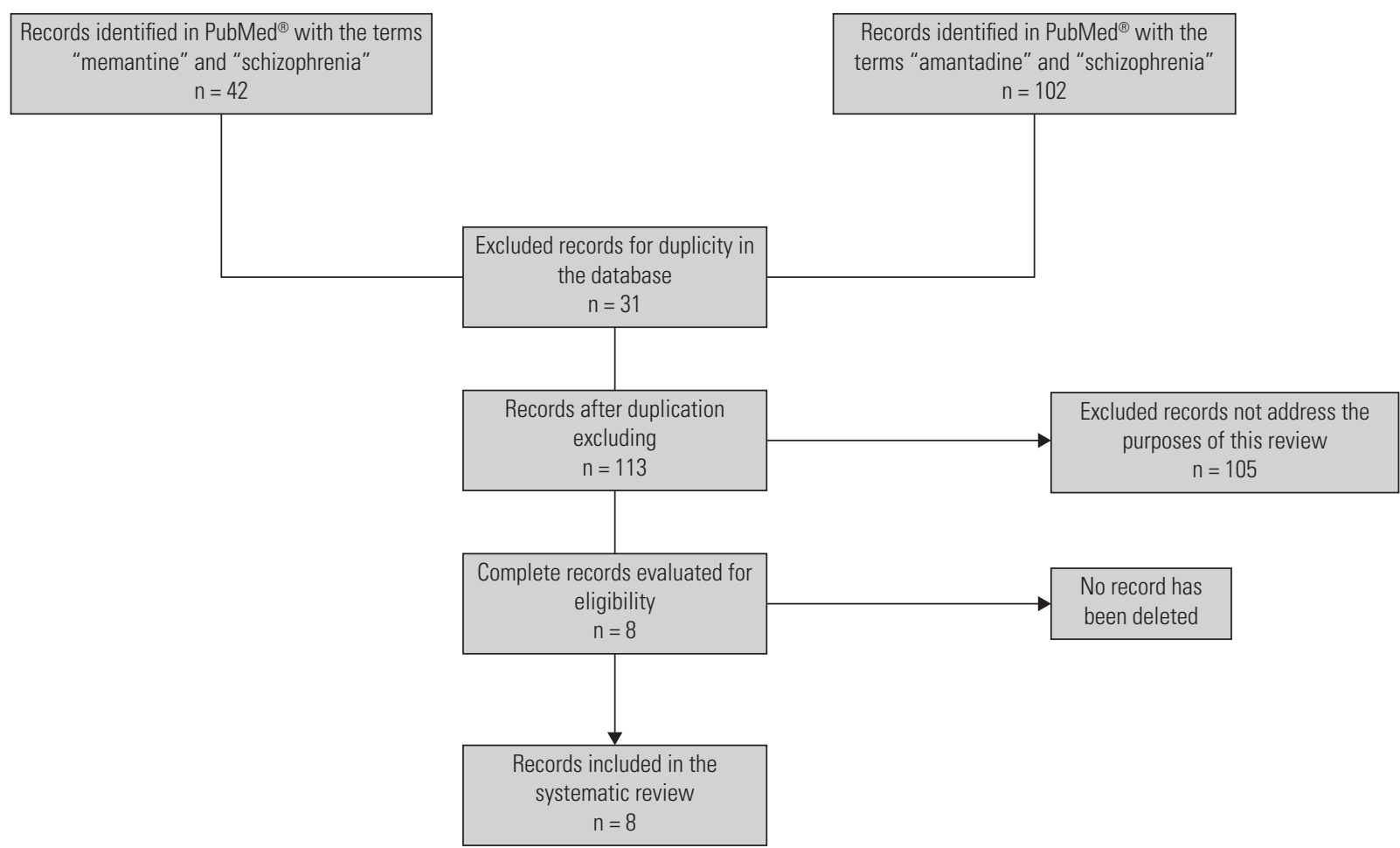

Figure 1. Systematic review flowchart: Flowchart for paper selection for this systematic review. 
A study conducted in Netherlands ${ }^{14}$ with 26 weeks duration and participation of 52 schizophrenic patients taking clozapine found that memantine use was associated with negative symptoms reduction, as assessed by PANSS Negative, compared to placebo. There was no statistically significant difference in PANSS total, positive and side effects occurrence between them.

Finally, Lucena et al. ${ }^{15}$, in a study conducted in Brazil, evaluating 21 patients with refractory schizophrenia, who were taking clozapine, verified that memantine addition to treatment regimen is associated with improvement in all aspects evaluated in Brief Psychiatry Rating Scale (BPRS). However, side effects incidence, Clinical Global Impressions and Mini-Mental State Examination (MMSE) score did not differ from that observed in placebo.

\section{Amantadine}

Were found 4 studies ${ }^{18-21}$ evaluated the amantadine use in association with various antipsychotics in patients with schizophrenia and schizoaffective disorder.

In the study conducted by Czepielewski et al. ${ }^{18}$ in Brazil, involving 20 patients and amantadine administration of $400 \mathrm{mg}$ per day, was verified better scores in Hopkins Verbal Learning Test-Revised in treated group with this drug compared to placebo. Moreover, Silver et al. ${ }^{21}$ found no improvement in clinical parameters of PANSS total and AIMS subdivisions with amantadine use.
Two Israeli studies ${ }^{19,20}$ evaluating biperiden or amantadine response in combination with antipsychotics in crossover noted that there were no significant changes between the groups with respect to PANSS negative and positive, BPRS scores and incidence of extrapyramidal symptoms with amantadine use in relation to biperiden, but there was a better score on Benton Visual Retention Test in amantadine treated group. The extrapyramidal symptoms incidence was higher in placebo group. The values found in MMSE and Weschler Memory Scale total score were not statistically significant between amantadine and biperiden use.

\section{Discussion}

In the last years the understanding of glutamatergic pathways involvement in schizophrenia etiopathogenesis has advanced dramatically, especially after the implication that aberrant NMDAr functioning plays in this condition ${ }^{4,19}$. Therefore, the search for drugs that modulate these receptors activity could hypothetically bring benefits, especially with regard to cognitive symptoms s, $,-7,10^{\text {. Although }}$ their mechanisms are not yet completely understood, amantadine and memantine are very interesting drugs because their ability to antagonize NMDAr and promoting a regulation in this pathological receptor activity without compromising the physiological action ${ }^{22}$. This property is already explored in Alzheimer disease treatment ${ }^{23,24}$, nevertheless, its use in schizophrenia is an initial objective of interest.

Table 1. Memantine and amantadine studies in schizophrenia: studies characteristics summary involving memantine and amantadine use in patients with schizophrenia

\begin{tabular}{|c|c|c|c|c|c|c|c|c|c|c|}
\hline Study & $\begin{array}{l}\text { Study } \\
\text { design }\end{array}$ & Diagnosis & $\begin{array}{c}\text { Diagnosis } \\
\text { criteria }\end{array}$ & $\begin{array}{l}\text { n (case/ } \\
\text { placebo) }\end{array}$ & $\begin{array}{l}\text { Duration } \\
\text { (week) }\end{array}$ & $\begin{array}{c}\text { Age } \\
\text { (years } \pm S D)\end{array}$ & $\operatorname{Men}(\%)$ & Drug & $\begin{array}{c}\text { Dose } \\
\text { (mg/day) }\end{array}$ & Outcomes \\
\hline \multicolumn{11}{|l|}{ Memantine } \\
\hline $\begin{array}{l}\text { Lieberman } \\
\text { et al., USA }{ }^{16}\end{array}$ & DBPCT & $\begin{array}{l}\text { Schizophrenia or } \\
\text { schizoaffective } \\
\text { disorder }\end{array}$ & DSM-IV & $69 / 67$ & 8 & $\begin{array}{c}\text { MEM: } \\
40,9 \pm 9,8 \\
\text { PLA: } \\
40,1 \pm 11,3\end{array}$ & $\begin{array}{l}\text { MEM: } 59.4 \\
\text { PLA: } 79.1\end{array}$ & $\begin{array}{c}\text { Memantine } \\
\text { + atypical } \\
\text { antipsychotics }\end{array}$ & 20 & $\begin{array}{c}\text { PANSS Total, Positive, Negative } \\
\text { and CDSS: MEM = PLA } \\
\text { SE: MEM > PLA }\end{array}$ \\
\hline $\begin{array}{l}\text { Rezaei et al., } \\
\text { Iran }{ }^{17}\end{array}$ & DBPCT & Schizophrenia & $\begin{array}{c}\text { DSM-IV- } \\
\text { TR }\end{array}$ & $20 / 20$ & 8 & $\begin{array}{c}\text { MEM: } \\
33,5 \pm 6,9 \\
\text { PLA: } \\
33,0 \pm 6,9\end{array}$ & $\begin{array}{l}\text { MEM: } 60 \\
\text { PLA: } 55\end{array}$ & $\begin{array}{c}\text { Memantine + } \\
\text { risperidone }\end{array}$ & 20 & $\begin{array}{c}\text { PANSS Total and Negative: } \\
\text { MEM > PLA } \\
\text { PANSS Positive, HDRS, ESRS } \\
\text { and SE: MEM = PLA }\end{array}$ \\
\hline $\begin{array}{l}\text { Veerman } \\
\text { et al., } \\
\text { Netherlands }{ }^{14}\end{array}$ & $\begin{array}{c}\text { DBPCT } \\
\text { (crossover) }\end{array}$ & Schizophrenia & DSM-IV & 52 & 26 & $42,35 \pm 9,55$ & 75 & $\begin{array}{c}\text { Memantine + } \\
\text { clozapine }\end{array}$ & 20 & $\begin{array}{c}\text { PANSS Total, Positive and SE: } \\
\text { MEM = PLA } \\
\text { PANSS Negative: } \\
\text { MEM > PLA }\end{array}$ \\
\hline $\begin{array}{l}\text { De Lucena } \\
\text { et al., Brazil15 }\end{array}$ & DBPCT & Schizophrenia & DSM-IV & $10 / 11$ & 12 & $\begin{array}{c}\text { MEM: } \\
34,67 \pm 9,04 \\
\text { PLA: - }\end{array}$ & $\begin{array}{c}\text { MEM: 90,5 } \\
\text { PLA: - }\end{array}$ & $\begin{array}{c}\text { Memantine + } \\
\text { clozapine }\end{array}$ & 20 & $\begin{array}{c}\text { BPRS Total, Positive and } \\
\text { Negative: MEM > PLA } \\
\text { SE, GCI e MMSE: MEM = PLA }\end{array}$ \\
\hline \multicolumn{11}{|l|}{ Amantadine } \\
\hline $\begin{array}{l}\text { Czepielewski } \\
\text { et al., Brazil|18 }\end{array}$ & DBPCT & Schizophrenia & DSM-IV & $9 / 11$ & 12 & $27,80 \pm 5,05$ & 75 & $\begin{array}{l}\text { Amantadine } \\
\text { + variable } \\
\text { antipsychotic }\end{array}$ & 400 & HVLT-R: AMA > PLA \\
\hline $\begin{array}{l}\text { Silver et al., } \\
\text { Israel } 21\end{array}$ & $\begin{array}{c}\text { DBPCT } \\
\text { (crossover) }\end{array}$ & $\begin{array}{l}\text { Schizophrenia or } \\
\text { schizoaffective } \\
\text { disorder }\end{array}$ & DSM-IV & 29 & 6 & $\begin{array}{c}36,86 \pm \\
10,77\end{array}$ & 75,86 & $\begin{array}{l}\text { Amantadine } \\
\text { + variable } \\
\text { antipsychotic }\end{array}$ & 200 & $\begin{array}{l}\text { Cognitive tests, PANSS Total, } \\
\text { Positive and Negative and } \\
\text { AIMS: AMA = PLA }\end{array}$ \\
\hline $\begin{array}{l}\text { Silver and } \\
\text { Geraisy, } \\
\text { Israel }{ }^{19}\end{array}$ & $\begin{array}{c}\text { DBPCT } \\
\text { (crossover) }\end{array}$ & Schizophrenia & DSM-III-R & 26 & 6 & $36,65 \pm 8,89$ & 69,23 & $\begin{array}{l}\text { Amantadine } \\
\text { or biperiden } \\
\text { + variable } \\
\text { antipsychotic }\end{array}$ & - & $\begin{array}{l}\text { PANSS Negative, Positive, } \\
\text { BPRS and ES: AMA = BIP } \\
\text { ES: PLA > AMA and BIP }\end{array}$ \\
\hline $\begin{array}{l}\text { Silver and } \\
\text { Geraisy, } \\
\text { Israel20 }\end{array}$ & $\begin{array}{c}\text { DBPCT } \\
\text { (crossover) }\end{array}$ & Schizophrenia & DSM-III-R & 26 & 6 & $36,65 \pm 8,89$ & 69,23 & $\begin{array}{l}\text { Amantadine } \\
\text { or biperiden } \\
\text { + variable } \\
\text { antipsychotic }\end{array}$ & $\begin{array}{l}\text { AMA: } \\
200 \\
\text { BIP: } 4\end{array}$ & $\begin{array}{c}\text { BVRT: AMA > BIP } \\
\text { MMSE and WMS Total: AMA } \\
=\text { BIP } \\
\text { WMS Subtest (Visual } \\
\text { reproduction): AMA > BIP }\end{array}$ \\
\hline
\end{tabular}

SD: standard deviation; DBPCT: double-blind placebo-controlled trials; DSM-IV: Diagnostic and Statistical Manual of Mental Disorders, Fourth Edition; DSM-IV-TR: Diagnostic and Statistical Manual of Mental Disorders, Fourth Edition, Text Revision; DSM-III-R: Diagnostic and Statistical Manual of Mental Disorders, Third Edition, Revised; MEM: memantine; AMA: amantadine; BIP: biperiden; PLA: placebo; PANSS: Positive and Negative Syndrome Scale; CDSS: Calgary Depression Scale for Schizophrenia; SE: side effects; HDRS: Hamilton Depression Rating Scale; ESRS: Extrapyramidal Symptom Rating Scale; BPRS: Brief Psychiatry Rating Scale; ES: extrapyramidal symptoms; MMSE: Mini-Mental State Examination; CGI: Clinical Global Impressions; HVLT-R: Hopkins Verbal Learning Test-Revised; AIMS: Abnormal Involuntary Movement Scale; WMS: Wechsler Memory Scale. 
Various studies have evaluated the clinical impact that amantadine and memantine use in schizophrenia treatment14-21. It is important to note that Lieberman et al. ${ }^{16}$ and Silver et al. ${ }^{21}$ studies included patients with schizoaffective disorder in memantine and amantadine clinical trials in their analysis, respectively.

Memantine studies showed in this review are double-blind placebo-controlled trials (DBPCT) ${ }^{15-17}$, but only one was conducted in a crossover design ${ }^{14}$. All trials used Diagnostic and Statistical Manual of Mental Disorders, fourth edition (DSM-IV) diagnosis criteria, except an Iranian research that used the revised version ${ }^{17}$. In all studies, memantine was associated with atypical antipsychotics, two of them used clozapine ${ }^{14,15}$.

Memantine showed to improve negative symptoms of schizophrenia assessed by PANSS 14,17, but not positive symptoms ${ }^{14,16}$. De Lucena et al. ${ }^{15}$ found an improvement in all three BPRS subscales. The data related to the incidence of side effects are divergent among the studies. Lieberman et al. ${ }^{16}$ found that they are more frequent in subjects taking memantine than placebo, while two other studies did not find this association ${ }^{14,17}$.

The studies involving amantadine were mostly DBPCT crossover ${ }^{18-21}$, one of which also included patients with schizoaffective disorder ${ }^{21}$ and two compared the efficacy of this drug with biperiden ${ }^{19,20}$. According to a Brazilian study ${ }^{18}$, patients with schizophrenia using amantadine showed better verbal learning and memory than the placebo group. In addition, the visual reproduction capacity was greater in patients using amantadine than biperiden ${ }^{21}$.

Both clinical trials have important limitations such as small number of patients and sparse follow-up period. The variety of antipsychotics and the scales used, especially in the studies involving the use of amantadine, make it difficult to compare them.

Thus, it would be essential to develop researches involving a larger number of patients with a longer follow-up and standardization of the used scales to evaluate the various symptomatic dimensions. Therefore, a more emphatic approach is necessary in this direction to elucidate the true role of these drugs as adjuncts to antipsychotic treatment since the data currently available in the scientific literature do not recommend its widespread use in clinical practice ${ }^{22}$.

\section{Ackowledgment}

We are grateful for the support of the Neurosciences program team of the Universidade Federal de Minas Gerais and the psychiatric residency program staffs of the Instituto Raul Soares.

\section{References}

1. Owen MJ, Sawa A, Mortensen PB. Schizophrenia. Lancet. 2016;388(10039):86-97.

2. Lopez AD, Murray CCJL. The global burden of disease, 1990-2020. Nat Med. 1998;4(11):1241-3.

3. Conley RR, Buchanan RW. Evaluation of treatment-resistant schizophrenia. Schizophr Bull. 1997;23(4):663-74.

4. Moghaddam B, Javitt D. From revolution to evolution: the glutamate hypothesis of schizophrenia and its implication for treatment. Neuropsychopharmacology. 2012;37(1):4-15.

5. Thiele A, Bellgrove MA. Neuromodulation of attention. Neuron. 2018;97(4):769-85.

6. Dauvermann MR, Lee G, Dawson N. Glutamatergic regulation of cognition and functional brain connectivity: insights from pharmacologi- cal, genetic and translational schizophrenia research. Br J Pharmacol. 2017;174(19):3136-60.

7. Gécz J. Glutamate receptors and learning and memory. Nat Genet. 2010;42(11):925-6.

8. Arundine M, Tymianski M. Molecular mechanisms of calcium-dependent neurodegeneration in excitotoxicity. Cell Calcium. 2003;34(45):325-37.

9. Traynelis SF, Wollmuth LP, McBain CJ, Menniti FS, Vance KM, Ogden KK, et al. Glutamate Receptor Ion Channels: Structure, Regulation, and Function. Pharmacol Rev. 2010;62(3):405-96.

10. Schwartz T, Sachdeva S, Stahl S. Glutamate neurocircuitry: theoretical underpinnings in schizophrenia. Front Pharmacol. 2012;3:195.

11. Javitt DC. Glutamate as a therapeutic target in psychiatric disorders. Mol Psychiatry. 2004;9(11):984-97, 979.

12. John JP, Lukose A, Manjunath S. Off-label use of memantine as adjunctive treatment in schizophrenia: a retrospective case series study. Pharmacopsychiatry. 2014;47(6):202-9.

13. Lipton SA. Paradigm shift in neuroprotection by NMDA receptor blockade: memantine and beyond. Nat Rev Drug Discov. 2006;5(2) 160-70.

14. Veerman SR, Schulte PF, Smith JD, de Haan L. Memantine augmentation in clozapine-refractory schizophrenia: a randomized double-blind, placebo-controlled crossover study. Psychol Med. 2016;46(9):1909-21.

15. de Lucena D, Fernandes BS, Berk M, Dodd S, Medeiros DW, Pedrini M, et al. Improvement of negative and positive symptoms in treatment-refractory schizophrenia: a double-blind, randomized, placebo-controlled trial with memantine as add-on therapy to clozapine. J Clin Psychiatry. 2009;70(10):1416-23.

16. Lieberman JA, Papadakis K, Csernansky J, Litman R, Volavka J, Jia XD, et al.; MEM-MD-29 Study Group. A randomized, placebo-controlled study of memantine as adjunctive treatment in patients with schizophrenia. Neuropsychopharmacology. 2009;34(5):1322-9.

17. Rezaei F, Mohammad-Karimi M, Seddighi S, Modabbernia A, Ashrafi $\mathrm{M}$, Salehi B, et al. Memantine add-on to risperidone for treatment of negative symptoms in patients with stable schizophrenia: randomized, double-blind, placebo-controlled study. J Clin Psychopharmacol. 2013;33(3):336-42.

18. Czepielewski LS, Sodre L, Souza AC, Bucker J, Burke KP, Cereser KM, et al. Changes in verbal learning of patients with schizophrenia: results from a randomized, double-blind, placebo-controlled trial of amantadine adjunctive to antipsychotics. Schizophr Res. 2015;168(1-2):571-2.

19. Silver $\mathrm{H}$, Geraisy N. No difference in the effect of biperiden and amantadine on negative symptoms in medicated chronic schizophrenic patients. Biol Psychiatry. 1995;38(6):413-5.

20. Silver H, Geraisy N. Effects of biperiden and amantadine on memory in medicated chronic schizophrenic patients. a double-blind cross-over study. Br J Psychiatry. 1995;166(2):241-3.

21. Silver H, Goodman C, Isakov V, Knoll G, Modai I. A double-blind, cross-over comparison of the effects of amantadine or placebo on visuomotor and cognitive function in medicated schizophrenia patients. Int Clin Psychopharmacol. 2005;20(6):319-26.

22. Kishi T, Iwata N. NMDA receptor antagonists interventions in schizophrenia: Meta-analysis of randomized, placebo-controlled trials. J Psychiatr Res. 2013;47(9):1143-9.

23. Kishi T, Matsunaga S, Oya K, Nomura I, Ikuta T, Iwata N. Memantine for Alzheimer's Disease: An Updated Systematic Review and Meta-analysis. J Alzheimers Dis. 2017;60(2):401-25.

24. McShane R, Westby MJ, Roberts E, Minakaran N, Schneider L, Farrimond LE, et al. Memantine for dementia. Cochrane Database Syst Rev. 2019;3:CD003154. 